\title{
Towards 'MOOCs with a Purpose': Crowdsourcing and analysing scalable design solutions with MOOC learners
}

Citation for published version (APA):

Van Rosmalen, P., Kasch, J., Kalz, M., Firssova, O., \& Brouns, F. (2017). Towards 'MOOCs with a Purpose': Crowdsourcing and analysing scalable design solutions with MOOC learners. In E. Lavoué, H. Drachsler, K. Verbert, J. Broisin, \& M. Pérez-Sanagustín (Eds.), Data Driven Approaches in Digital Education: 12th European Conference on Technology Enhanced Learning, EC-TEL 2017, Tallinn, Estonia, September 12-15, 2017, Proceedings (pp. 486-491). Springer International Publishing AG. Lecture Notes in Computer Science Vol. 10474 https://doi.org/10.1007/978-3-319-66610-5_47

\section{DOI:}

10.1007/978-3-319-66610-5_47

Document status and date:

Published: 01/09/2017

Document Version:

Peer reviewed version

Document license:

CC BY-SA

Please check the document version of this publication:

- A submitted manuscript is the version of the article upon submission and before peer-review. There can be important differences between the submitted version and the official published version of record. People interested in the research are advised to contact the author for the final version of the publication, or visit the DOI to the publisher's website.

- The final author version and the galley proof are versions of the publication after peer review.

- The final published version features the final layout of the paper including the volume, issue and page numbers.

Link to publication

\section{General rights}

Copyright and moral rights for the publications made accessible in the public portal are retained by the authors and/or other copyright owners and it is a condition of accessing publications that users recognise and abide by the legal requirements associated with these rights.

- Users may download and print one copy of any publication from the public portal for the purpose of private study or research.

- You may not further distribute the material or use it for any profit-making activity or commercial gain

- You may freely distribute the URL identifying the publication in the public portal.

If the publication is distributed under the terms of Article $25 f a$ of the Dutch Copyright Act, indicated by the "Taverne" license above, please follow below link for the End User Agreement:

https://www.ou.nl/taverne-agreement

Take down policy

If you believe that this document breaches copyright please contact us at:

pure-support@ou.nl

providing details and we will investigate your claim.

Downloaded from https://research.ou.nl/ on date: 26 Apr. 2023 
Preprint: Van Rosmalen, P., Kasch, J., Kalz, M., Firssova, O., \& Brouns, F. (2017). Towards 'MOOCs with a Purpose': Crowdsourcing and analysing scalable design solutions with MOOC learners. EC-TEL 2017, LNCS 10474

\title{
Towards 'MOOCs with a Purpose': Crowdsourcing and analysing scalable design solutions with MOOC learners
}

\author{
Peter van Rosmalen ${ }^{1}$, Julia Kasch ${ }^{1}$, Marco Kalz ${ }^{2}$, Olga Firssova ${ }^{1}$ and Francis Brouns ${ }^{1}$ \\ ${ }^{1}$ Welten Institute, Faculty of Psychology and Educational Sciences \\ ${ }^{2}$ UNESCO chair of Open Education, Faculty Management, Science and Technology and Wel- \\ ten Institute, Faculty of Psychology and Educational Sciences \\ Open University of the Netherlands, Heerlen, The Netherlands \\ \{peter.vanrosmalen, julia.kasch, marco.kalz, olga.firssova, francis. \\ brouns\}@ou.nl
}

\begin{abstract}
In this study we explored the use of a research assignment on instructional design of MOOCs by MOOC students. The use of a research assignment was expected to be of interest for both students and the designer. The assignment is based on a framework to analyse MOOC designs with the objective to identify best practices. It builds on four principles: constructive alignment, task complexity, interaction and formative feedback. The exploration indicates that students positively appreciate this kind of assignments. Moreover, the crowdsourcing alike approach showed to be a valuable way for MOOC designers to get awarded with data gathered by their participants. The participants, be it a small sample, were able to apply the framework to analyse MOOCs and identify best practices. We will discuss the framework and the results of its application. Finally, we will conclude with the experiences of the users.
\end{abstract}

Keywords: MOOC design, Educational Scalability, MOOCs With A Purpose, Constructive Alignment, Task Complexity, Interaction, Formative feedback.

\section{Introduction}

Nowadays there is an increase of demand for the Higher Education Area expected, leading to questions of scalability of the educational system as a whole. "Taking note that 414.2 million students will be enrolled in higher education around the world by 2030 - an increase from 99.4 million in 2000, and that online, open and flexible education is going mainstream, the importance of quality learning outcomes for learners cannot be overestimated.” [1]. Delivery at scale has been the essence of the founding missions of the many national Open University systems established from the 70s onwards. However, at the moment Massive Open Online Courses (MOOCs) seem to have been taken up as a new format of digital learning and teaching for delivery at scale [2]. According to latest statistics from the end of 2016 there are 58 Million learners enrolled in more than 7000 courses from more than 1000 institutions [3]. The potential of MOOCs to enable more people around the world with different learner 
profiles and educational backgrounds to access (higher) education supports the idea of lifelong learning [4]. Moreover, since MOOC designs are open, and therewith can be compared against criteria, they have a potential as a source of less teacher-supportdemanding designs in regular education. However, while MOOCs enable large numbers of people to access (higher) education materials, unlike the Open Universities', it is less clear at which level their offerings are supported. A common pattern in MOOCs is the provision of video lectures and multiple choice quizzes [2]. While this approach might have the potential to be a scalable solution, a critical question is which complexity levels of learning and skill acquisition are supported. The design of a final assignment is challenging, in particular, when it has to meet the higher complexity levels of learning. Therefore, in this study we explored how to set-up a final assignment in a MOOC that fits with higher complexity levels of learning and combines the interest of the student and the designer (teacher). For the learner, as in any design, the assignment should correspond with the course and the level of its objectives. However, in particular since most of the time there are no official credits, it also should challenge and motivate them and contribute to their knowledge. For the designer, as an additional constraint, we expect the outcomes of the assignment to contribute to their research. Contributions of the public to research are spread over many domains (www.citizenscience.org). It is common to research behaviour and motivation of MOOC participants, however, also 'MOOCs with a purpose' start emerging $[5,6]$. In this study our aims are twofold i.e. to use MOOCs as an instrument to support research. For a designer this is an incentive to develop a MOOC. Since it gives access to a potentially large number of contributors, a relatively simple and convenient way to collect data and, in general, a well-educated audience. For the learner, research based tasks can support deep learning and application of the new knowledge and skills, thus enriching the learning experience.

The research assignment, links to the question of scalability of the educational system introduced above. It was based on a framework [7] developed to analyse the educational scalability of MOOCs and to detect best practice. MOOC participants were asked as part of their final assignment to analyse a MOOC of their choice with the help of the framework. This assignment did build on the MOOC's contents and had the objective to give the participants an active insight in MOOC design practice. For the designers the results of the assignment should give insight in the validity of the framework and should yield examples of design practice. The next sections introduces the framework, followed by the study and its results, and a discussion.

\section{A Framework to Detect and Analyse Educational Scalability}

The literature on quality and design guidelines related to MOOCs is very extensive taking into account many criteria including organizational ones such as institutional organization and a minimal staff student ratio [8, 9]. However, they seem to disregard that MOOCs are another type of educational offering as they also use criteria related to e.g. institutional organisation and to staff size and roles. Moreover, mostly, they serve one of two purposes: either they offer design guidelines or they provide criteria 
which are used to assess the design. Instead we focussed on just four main criteria commonly agreed upon in the literature as being essential for learning. Our main objective is not to assess or prescribe design guidelines but to use the design criteria to study/identify best practice. In summary, the framework [7] has been based on the following four criteria:

- Constructive alignment: as an overall necessity since it implies coherence and structure [10,11]. Aligned course design is based on clearly stated learning goals, corresponding learning activities and are assessed by appropriate assessment methods. For students, alignment helps to select the appropriate course and to regulate their learning. Particularly in a MOOC context which lacks the constraints of a curriculum and general academic requirements related to institutional policies and habits.

- Task complexity: courses should offer variation of different learning activities on various complexity levels. They should provide learning activities in the context of real-world problems which ask students to apply their knowledge and skills $[12,13]$. Best practice will give insight in task complexity in existing courses, assist development of new courses and give input to further research.

- Interaction promotes learning and therefore should be a part of the learning process [3, 13, 14]. In MOOCs, interaction can take place between students (S-S), student and teacher (S-T) or student and content (S-C). Best practice will help to see how large numbers of students can be supported with different interaction types.

- $\quad$ Formative assessment \& feedback: should be part of the learning process, it improves and supports learning [15]. Again, current practices can help us to understand what are the options to provide students with (personalized) feedback [16].

To make the framework fit for use as an assignment, it was translated into a survey. The survey contained a total of 64 questions both open and closed questions, divided over 5 main sections: (1) general information about the MOOC and the unit of learning (UoL) selected; (2) (the degree of) constructive alignment of the UoL.; (3) the type and use of interactions i.e. S-S, S-T and S-C; (4) the use and details of formative assessment and feedback. (5) general demographics of the students and feedback on the assignment. In addition, the survey contained a section on informed consent, in which the learner was asked to confirm they did read the information about the research and that their participation was voluntary. In any case, they could choose to withdraw at any time. Finally, each section was supported by a short introduction explaining the purpose of the section and background to introduce the questions.

\section{$3 \quad$ Method and Materials}

The study was situated in the MOOC 'Assessment for learning in practice' focussing on theory and guidelines on the topic of formative assessment. The target audience was teachers and educationalists. Two assignments focused on the use of the above introduced framework. The first assignment was an exercise to train the use of the survey. For this the learners used part of the survey to analyse the third lesson of the MOOC itself. The second assignment was the final assignment of the MOOC. The learners were asked to select a MOOC of their choice and to analyse it with the sur- 
vey. To limit the size of the assignment, the students only had to analyse one UoL of the MOOC. The UoL had to comply with two constraints: it should contain formative assessment and it should not be the first or last week of the MOOC.

The MOOC was offered on the EMMA platform (platform.europeanmoocs.eu). The level of activity varied strongly, lesson views went from 199 students (lesson 1) to 101 students (lesson 4). The final lesson (lesson 7) that contained the final assignment was viewed by 38 students of which 11 handed in the final assignment.

\section{$4 \quad$ Results and Discussion}

Eleven students (9 female, 2 male) completed the survey, with participants from Italy, Germany, the Netherlands and Spain and an age range between 29-58. All did have a professional background in (higher) education and/or research. Five of the participants reported on their prior experience with MOOCs and indicated that they (co)designed one or more MOOCs.

The MOOCs analysed showed to be representative given the variety of designs, the range of topics, durations and platforms supported. In most cases $(n=9)$ the participants indicated that the learning goals of the MOOCs they analysed were provided and of different levels (5 on the "does"/“shows how" level; 6 on the "knows", "knows how" levels of Miller). Seven of the MOOCs indicated the prior knowledge expected to successfully follow the MOOC. The UoL selected for further analysis was respectively in week $2(5 x), 3(4 x), 5(1 x)$ and in week $12(1 x)$.

Constructive alignment was analysed by comparing the level of the learning goals according to Miller's classification and the learning activities in a UoL. Goals and activities are aligned when there was at least one activity at the goal level. According to the participants in 6 of the 11 cases the learning goals of the UoL were aligned with the learning activities. The assignment of the Miller level to learning goals and activities, however, was not always consistent within each survey. The descriptions added, indicated that, in particular, the learning goals were only very superficially defined in the MOOCs making it difficult, if at all possible, to assign a Miller level to them.

For the learning activity analysis, the students had to indicate the type and complexity of the provided learning activities and describe them. The activities covered a wide spectrum including reading assignments, video lectures, audio recording, essays, blogposts and design activities, quizzes with open and closed questions, simulations and games, group assignments and brainstorm activities. The designs varied, partly reflecting the level of the learning goal/learning activity, i.e. higher level activities were more connected with activities such as essays, design activities, quizzes with open questions, simulations and games, group assignments and brainstorm activities; lower level activities with reading assignments, video lectures and closed questions. The activities connected to higher level learning activities suggest that MOOCs can contribute to best practice, examples included: collaborating on mind-maps and OER, and sharing examples of soil crusting in students' local neighbourhood.

For the interactions, the students had to indicate if an interaction type was used and give a description. S-S interaction (8x) varied between group work, peer feedback, 
forum exchanges and the use of Facebook. S-T interaction (7x) included questions during live sessions and forum exchanges. In some cases the interaction type was ambiguous e.g. for some students it was unclear whether a pre-designed tutor video is $\mathrm{S}$-T or S-C interaction. While all interactions types were represented, the descriptions indicated that the main focus was on S-C interaction followed by S-S interaction.

Formative feedback was analysed at a relatively high level of detail. In 8 cases the UoL contained activities with formative feedback, partly by the learning material (quizzes, simulations) and partly by peers. In one case selected examples were commented upon by the tutor. While peer feedback was indicated 5 times, other than a worked out example $(1 \mathrm{x})$ there was no support or preparation to prime the learner. No practice was reported that could contribute to best practice.

User experiences. The students completed the final assignment within one hour (6x), within two hours (2x), within four hours (2x) and finally 1 student used over six hours. Nine students expressed feedback on the final assignment. Two indicated that it was too long and one student had "no feedback", six of them were clearly positive as is shown by:

- "I appreciate this final assignment; the analysis template is helpful and covers important aspects of formative assessment", and

- "It is an interesting approach: I had never thought about how to analyse a MOOC and since I have done a lot of MOOCs now I realize that some are not wellfocussed and need bettering as regards formative and summative feedback".

\section{Conclusion}

In this paper we explored the use of a research assignment as a final assignment of a MOOC for the benefits of student and designer. Students were positive on the assignment. For the designers, overall, the results were positive, i.e. the crowd-sourced approach showed viable and the framework was applicable and did expose examples of best practice, in particular, for learner activities. The results of the analyses confirmed that MOOCs, in general, are still weak in various aspects of their design. However, unlike the use of existing frameworks [8, 9], it also revealed practices that can be of interest to MOOC or (online) learning designers. With individual respondents participating, the clarity of the survey questions is of utmost importance to assure the validity of the outcome. Some question/answer options showed to be ambiguous, in particular since the information in the MOOC analysed is often ambiguous too. This will require an update of the survey. Another issue was the number of responses. Alike many MOOCs the completion rate was low. However, to establish a representative sample in our case we would like to have had an analysis of at least 50 learners. Finally, depending of the assignment one has to be aware that there is a risk of bias with regard to who participates. Overall, however, the use of the framework showed to be of interest and its focus on best practice an interesting addition to existing frameworks. Finally, at a general level, the use of crowd-sourced research assignments has a clear potential for further exploration both for students and designers. 


\section{Acknowledgements}

This work is supported by the Dutch National Initiative for Education Research / The Netherlands Organisation for Scientific Research and the Dutch Ministry of Education, Culture and Science under grant 405-15-705 (www.sooner.nu).

\section{References}

1. Ossiannilsson, E., Williams, K., Camilleri, A., Brown, M.: Quality Models in Online and Open Education around the Globe: State of the Art and Recommendations (2015)

2. Yuan, L., Powell, S.: MOOCs and Open Education: Implications for Higher Education. A white paper. JISC Cetis, 1-21, (2013)

3. Class-Central (2016).

4. Kalz, M.: Lifelong Learning and Its Support with New Technologies. In Wright, J. D. (Ed). International Encyclopedia of the Social \& Behavioral Sciences (pp. 93-99).(Vol. 14) (2nd ed.). Oxford: Elsevier (2015)

5. Zimmermann, C., Kopp, M., Ebner, M.: How MOOCs can be used as an instrument of scientific research. In Khalil, M, Ebner, M., Kopp, M., Lorenz, A., Kalz, M. (Eds.) Proceedings of the EMOOCs 2016, pp. 393-400, (2016)

6. Hodge, R: Adapting a MOOC for Research: Lessons Learned from the First Presentation of Literature and Mental Health: Reading for Wellbeing. Journal of Interactive Media in Education, 2016(1): 19, pp. 1-17, (2016)

7. Kasch, J., Van Rosmalen, P., Kalz, M.: Learning at Scale: Educational Scalability of Open Courses (submitted)

8. Rosewell, J., Jansen, D.: The OpenupEd quality label. Benchmarks for MOOCs. The International Journal for Innovation and Quality in Learning, 88-100, (2014)

9. Margaryan, A., Bianco, M., Littlejohn, A.: Instructional quality of Massive Open Online Courses (MOOCs), Computers \& Education, 80, 77-83, (2015)

10. Biggs, J.: Aligning teaching for constructing learning. The Higher Education Academy, 1-4, (2003)

11. Blumberg, P.: Maximizing Learning Through Course Alignment and Experience with Different Types of Knowledge. Innovative Higher Education, 34, 93-103, (2009)

12. Miller, G.: The assessment of clinical skills/competence/performance. Academic Medicine, 65 (1990)

13. Merrill, M.D.: First principles of instruction: Identifying and designing effective efficient and engaging instruction. Hoboken, NJ: Pfeiffer/John Wiley \& Sons, (2013)

14. Anderson, T.: Toward a theory of online learning. In T. Anderson and F. Elloumi (eds.), Theory and practice of online learning. Athabasca University, Athabasca, Canada, 33-60, (2004)

15. Floratos, N., Guasch, T., Espasa, A.: Recommendations on Formative Assessment and Feedback Practices for stronger engagement in MOOCs. Open Praxis, 7, 141-152, (2015)

16. Dolan, V.: Massive online obsessive compulsion: What are they saying out there about the latest phenomenon in higher education? International Review of Research in Open and Distributed Learning, 15(2), 268-281, (2014) 